\title{
Erratum to microRNA-188 aggravates contrast-induced apoptosis by targeting SRSF7 in novel isotonic contrast-induced acute kidney injury rat models and renal tubular epithelial cells
}

\author{
Bowen Liu ${ }^{1,2 \#}$, Yunfei Chai ${ }^{1,3 \#}$, Wei Guo ${ }^{1,4 \#}$, Kaiyan Lin $^{5 \#}$, Shiqun Chen ${ }^{1,2 \#}$, Jin Liu ${ }^{2}$, Guoli Sun ${ }^{1,2}$, \\ Guangzhong Chen ${ }^{1,2}$, Feier Song ${ }^{2}$, Yibo $\mathrm{He}^{2}$, Yan Liang ${ }^{6}$, Zhaodong $\mathrm{Guo}^{2}$, Li Lei ${ }^{2,3}$, Lihao $\mathrm{He}^{1,2}$, \\ Liwei Liu ${ }^{2}$, Ning Tan ${ }^{1,2,3}$, Yong Liu ${ }^{1,2,7}$, Shilong Zhong ${ }^{1,2,7}$, Jiyan Chen ${ }^{1,2,7}$ \\ ${ }^{1}$ Guangdong Provincial People's Hospital, School of Medicine, South China University of Technology, Guangzhou 510000, China; ${ }^{2}$ Department \\ of Cardiology, Guangdong Provincial Key Laboratory of Coronary Heart Disease Prevention, Guangdong Cardiovascular Institute, ${ }^{3}$ Department \\ of Anesthesiology, Cardiovascular Institute of Guangdong Province, ${ }^{4}$ Guangdong Geriatrics Institute, Guangdong Provincial People's Hospital, \\ Guangdong Academy of Medical Sciences, Guangzhou 510100, China; ${ }^{5}$ Department of Cardiology, Fujian Provincial Hospital, Fujian Medical \\ University, Fujian Cardiovascular Institute, Fuzhou 350001, China; ${ }^{6}$ Department of Cardiology, Maoming People's Hospital, Maoming 525000, \\ China; ${ }^{7}$ The Second School of Clinical Medicine, Southern Medical University, Guangzhou 510515, China \\ Contributions: (I) Conception and design: B Liu, Y Chai, W Guo, K Lin, S Chen, Y Liu, S Zhong, J Chen; (II) Administrative support: B Liu, Y Chai, \\ W Guo, K Lin, S Chen; (III) Provision of study materials or patients: All authors; (IV) Collection and assembly of data: All authors; (V) Data analysis \\ and interpretation: All authors; (VI) Manuscript writing: All authors; (VII) Final approval of manuscript: All authors. \\ \#These authors contributed equally to this work. \\ Correspondence to: Yong Liu, MD, PhD; Shilong Zhong, MD, PhD; Jiyan Chen, MD, FACC, FESC. Department of Cardiology, Guangdong \\ Provincial Key Laboratory of Coronary Heart Disease Prevention, Guangdong Cardiovascular Institute, Guangdong Provincial Hospital Affiliated \\ to South China University of Technology, Guangdong Academy of Medical Sciences, Guangzhou 510100, China. Email: liuyong2099@126.com; \\ zhongsl@hotmail.com; chenjiyandr@126.com.
}

doi: $10.21037 /$ atm-2020-45

View this article at: http://dx.doi.org/10.21037/atm-2020-45

Erratum to: Ann Transl Med 2019;7:378

MicroRNA-188 aggravates contrast-induced apoptosis by targeting SRSF7 in novel isotonic contrast-induced acute kidney injury rat models and renal tubular epithelial cells

In the article entitled "MicroRNA-188 aggravates contrast-induced apoptosis by targeting SRSF7 in novel isotonic contrastinduced acute kidney injury rat models and renal tubular epithelial cells" (1), there is an error.

In Figure 1C, the pathological changes of renal tissues of rats was wrongly presented and the corrected version is as follows: 

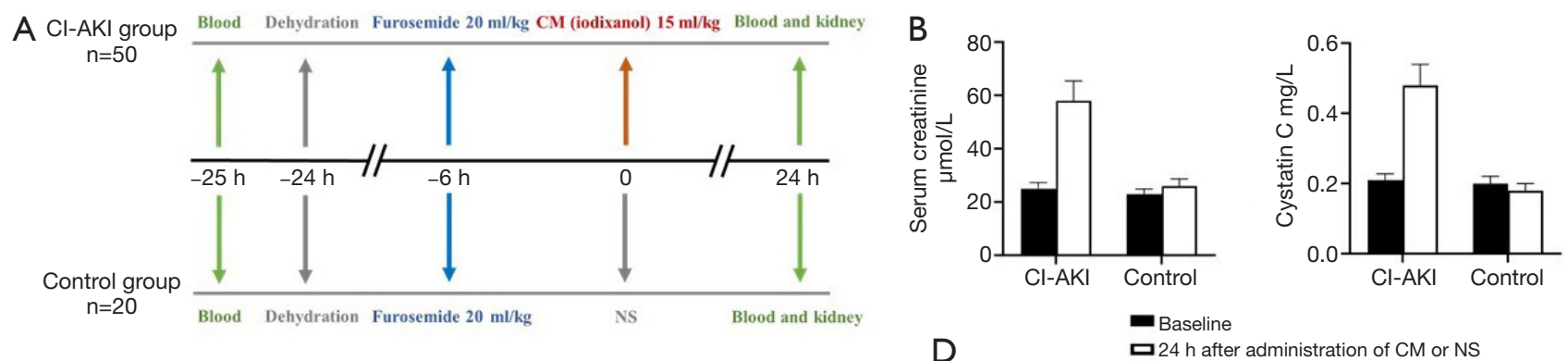

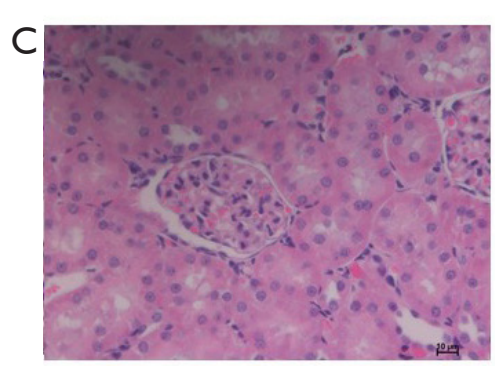

Control

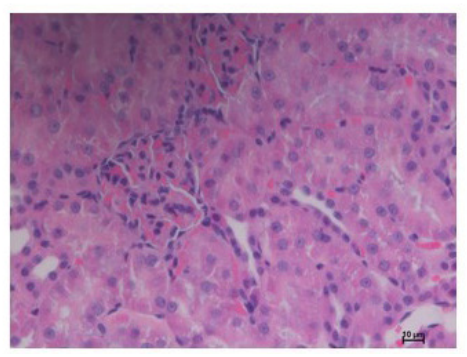

Cl-AKI

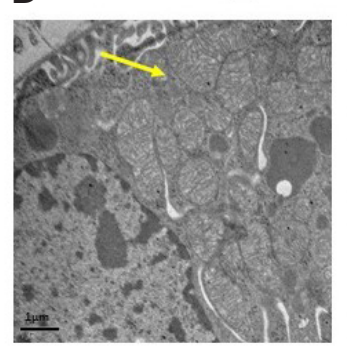

Control

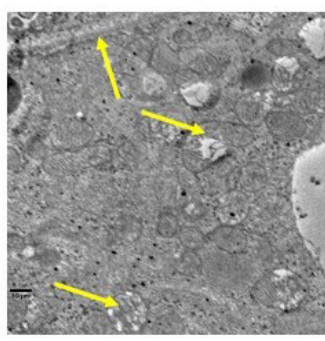

Cl-AKI

Figure 1 Successful establishment of isotonic CI-AKI rat model. (A) Experimental grouping and operation procedures of establishing the isotonic CI-AKI rat model (CI-AKI group) and control group; (B) serum creatinine (Scr) and cystatin C (Cys C) levels of rats; the measurement data were expressed as mean \pm standard deviation; $(\mathrm{C})$ pathological changes of renal tissues of rats detected and evaluated by HE staining (400x; scale bar =25 $\mu \mathrm{m}$ ); (D) subcellular changes of renal tissues of rats detected and evaluated by electron microscope. Yellow arrow in control group shows normal mitochondrion. While yellow arrows in CI-AKI group shows glomerular basement membrane thicken and mitochondrion swelling.

We regret the error.

Open Access Statement: This is an Open Access article distributed in accordance with the Creative Commons AttributionNonCommercial-NoDerivs 4.0 International License (CC BY-NC-ND 4.0), which permits the non-commercial replication and distribution of the article with the strict proviso that no changes or edits are made and the original work is properly cited (including links to both the formal publication through the relevant DOI and the license). See: https://creativecommons.org/licenses/by-ncnd/4.0/.

\section{References}

1. Liu B, Chai Y, Guo W, et al. MicroRNA-188 aggravates contrast-induced apoptosis by targeting SRSF7 in novel isotonic contrast-induced acute kidney injury rat models and renal tubular epithelial cells. Ann Transl Med 2019;7:378.

Cite this article as: Liu B, Chai Y, Guo W, Lin K, Chen S, Liu J, Sun G, Chen G, Song F, He Y, Liang Y, Guo Z, Lei L, He L, Liu L, Tan N, Liu Y, Zhong S, Chen J. Erratum to microRNA-188 aggravates contrast-induced apoptosis by targeting SRSF7 in novel isotonic contrast-induced acute kidney injury rat models and renal tubular epithelial cells. Ann Transl Med 2021;9(3):275. doi: 10.21037/atm-2020-45 